\title{
Real-time, simulation-enhanced interprofessional education in the care of older adults with multiple chronic comorbidities: a utilization-focused evaluation
}

\author{
Charles P. Tilley ${ }^{1,2}$, Janna Roitman ${ }^{3}$, Kimberly P. Zafra ${ }^{4}$, Mary Brennan ${ }^{2}$ \\ ${ }^{1}$ Department of Nursing, Calvary Hospital and Hospice, The Bronx, NY, USA; ${ }^{2}$ New York University Rory Meyers College of Nursing, New York, \\ NY, USA; ${ }^{3}$ Long Island University (LIU) Arnold \& Marie Schwartz College of Pharmacy and Health Sciences, Brooklyn, NY, USA; ${ }^{4}$ Mount Sinai \\ Hospital Medical ICU, New York, NY, USA \\ Contributions: (I) Conception and design: CP Tilley, J Roitman; (II) Administrative support: None; (III) Provision of study materials or patients: \\ CP Tilley, J Roitman; (IV) Collection and assembly of data: CP Tilley, J Roitman; (V) Data analysis and interpretation: CP Tilley, J Roitman, M \\ Brennan; (VI) Manuscript writing: All authors; (VII) Final approval of manuscript: All authors. \\ Correspondence to: Charles P. Tilley, MS, ANP-BC, ACHPN, CWOCN. Department of Nursing, Calvary Hospital and Hospice, The Bronx, NY, \\ USA; New York University Rory Meyers College of Nursing, New York, 433 First Avenue, NY 10010, USA. Email: tillec01@nyu.edu.
}

Background: Interprofessional education (IPE) is a curricular requirement for all healthcare professional education standards. To foster learning about, from and with each other, consistent with the Interprofessional Education Consortium's Core Competencies, many graduate schools are integrating interprofessional (IP) simulation experiences throughout their educational curricula, providing multiple opportunities for health professional students to collaborate and practice together. High-fidelity, real-time simulations help students from diverse professional backgrounds to apply their classroom learning in realistic clinical situations, utilize mobile technology to access clinical decision support (CDS) software, and receive feedback in a safe setting, ensuring they are practice-ready upon graduation.

Methods: New York University Rory Meyers College of Nursing (NYU) and Long Island University College of Pharmacy (LIU) partnered for two consecutive years to create, coordinate and implement two interprofessional educational simulations involving patients with chronic cardiovascular disease. A utilizationfocused evaluation of high-fidelity, simulation-enhanced IPE (Sim-IPE) was implemented to assess students' IP competencies before and after their participation in the IPE-simulation and their overall satisfaction with the experience. The Interprofessional Collaborative Competency Attainment Survey (ICCAS), a reliable instrument, was administered to both doctor of pharmacy students and primary care advanced practice nursing students before and after each simulation experience. Additionally, student satisfaction surveys were administered following the IPE-simulation.

Results: Aggregated means revealed statistically significant improvements in each of the six domains including communication, collaboration, roles and responsibilities, collaborative patient/family approach, conflict resolution and team functioning. Student ratings revealed positive experiences with the IPE-simulations.

Conclusions: High-fidelity, real-time IPE-simulation is a powerful pedagogy to help graduate students from different professional backgrounds practice applying IP competencies in simulated experiences. Quality improvement studies and research studies are needed to assess the impact of high-fidelity, real-time simulations throughout graduate curricula with different types of patients to improve coordinated, team approaches to treatment.

Keywords: High-fidelity simulation; interprofessional education (IPE); clinical decision support (CDS); mobile technology

Received: 22 October 2019; Accepted: 01 June 2020; Published: 20 January 2021.

doi: $10.21037 /$ mhealth-19-216

View this article at: http://dx.doi.org/10.21037/mhealth-19-216 


\section{Introduction}

Interprofessional education (IPE) occurs, as stated by World Health Organization (WHO) in 2010, when students from two or more professions "learn about, from, and with each other" in a collaborative environment with a shared goal of improving patient care $(1,2)$. IPE activities help healthcare profession students to learn and appreciate their profession's unique scope of practice and how it integrates with the other health professions, improves communication skills which enables them to collectively identify healthcare problems, minimize medication and medical errors and find solutions to problems more expeditiously than they would independently (1-4). This article discusses findings from a 2-year, utilization focused evaluation of high-fidelity, simulation-enhanced IPE (Sim-IPE) that incorporated mobile health technology to educate nurse practitioner (NP) and pharmacy students to care for older adults with comorbid hypertension, diabetes, hyperlipidemia and tobacco dependence.

\section{Simulation}

In 2009, an expert panel of representatives from different health professions (dentistry, nursing, medicine, osteopathic medicine, pharmacy, and public health), named the Interprofessional Education Collaborative (IPEC), developed core competencies and sub-competencies to help guide IPE curriculum development across health professional schools (3). The "Four Core Competency Domains" include values and ethics for interprofessional (IP) practice, roles and responsibilities, IP communication, and teams and teamwork (3).

The Accreditation Council for Pharmacy Education (ACPE) requires (as an accreditation standard for all colleges of pharmacy) that all Doctor of Pharmacy (PharmD) students participate in formalized IPE programs (5). ACPE specifically states that in their guidance "all students are to provide entrylevel, patient-centered care in a variety of practice settings as a contributing member of an IP team" (5). In the aggregate, team exposure includes prescribers as well as other healthcare professionals (5). Similarly, The Commission on Collegiate Nursing Education (CCNE) standards for accreditation of graduate nursing programs also includes information and guidance on IPE and team-based modules of care, and encourages that education programs include planned clinical experiences that foster IP collaborative practice (6).
Differences in clinical requirements exist between the curricular and education standards among the healthcare professions. The ACPE in 2012 published "Guidance for the Accreditation Standards" and indicated that pharmacy colleges and schools may choose to include simulation experience as part of the overall Introductory Pharmacy Practice Experience (IPPE) in PharmD degree programs, however simulation hours do not substitute the 150 hours of required IPPE time in community and institutional health-system settings (5). Simulation-based pharmacy education has shown to improve students' knowledge, reinforce clinical performance and critical thinking, and decrease medication related errors (4,7-9). Studies show that participation in simulation activities can help preparing students for entry into the workforce as competent practitioners $(7,8)$.

Similarly, while simulation experiences are recommended in advanced practice nurses' (APRNs') education, they may not substitute for actual clinical hours (10). The Criteria for Evaluation of Nurse Practitioner Programs [2016] requires NP students to perform 500 direct care clinical hours, supervised by a preceptor, to achieve attainment of the NP core and population-focused competencies (10). Students may not substitute simulation hours for the 500 direct care hours, but simulation experiences are encouraged to complement the direct care hours. The decision to exclude simulation hours for direct clinical hours is based on the lack of research supporting simulation hours in the attainment of clinical competency (10).

\section{High-fidelity simulation}

High-fidelity simulation is a skill development pedagogy that uses human standardized patients and advanced technology to imitate realistic clinical scenarios (11). SimIPE is at the intersection of the pedagogy of simulation and IPE and prepares students to function as part of an IP team and carry learned knowledge, skills, and values into future collaborative practice (12).

High-fidelity, simulation-enhanced IP experiential learning is an effective way to translate the theoretical management of patients with multiple, chronic cardiovascular conditions to the clinical setting $(12,13)$. Several studies show that simulation-based clinical education not only improves conceptual learning outcomes for health profession students, but also develops their clinical judgment and performance and increases their confidence in teamwork skills and interdisciplinary collaboration $(13,14)$. In June 2016, the Society for Simulation in Healthcare 
published the first "Healthcare Simulation Dictionary", where it defined simulation-based learning experience as "structured activities that represent actual or potential situations in education and practice" (15). High-fidelity simulation is a potent teaching-learning strategy that augments nursing and pharmacy students' clinical competence, confidence, critical thinking, knowledge, clinical reasoning, communication skills, motivation, and clinical judgment (2-4,12-14).

\section{Chronic cardiovascular illness}

Eighty percent of people aged 65 years or older have one or more chronic illnesses; $25 \%$ of these people will be diagnosed with four or more chronic conditions in their lifetime (16-18). Cardiovascular disease and diabetes will account for an overwhelming percentage of chronic illnesses suffered by these older adults (18-20). A combination of lifestyle modification and pharmacological management is the mainstay of treatment for this population (17-19). Unfortunately, most people with hypertension, diabetes, hyperlipidemia and tobacco dependence receive inadequate, often fragmented primary care $(19,20)$. Therefore, IP collaboration between primary care providers and pharmacists offers a sensible and effective way of delivering comprehensive, coordinated care to these complex chronic disease states patient population.

To address an urgent need to educationally prepare health professionals for an integrated team approach upon graduation, there are a multitude of new innovative IP teaching strategies in both advanced practice nursing and pharmacy curricula that specifically focus on the care of older adults with multiple, chronic cardiovascular conditions in the outpatient setting. The use of high-fidelity, SimIPE is an effective pedagogical approach designed to teach APRN and pharmacy students to collaboratively manage patients with multiple chronic cardiovascular conditions.

\section{Setting}

In 2018 and 2019, the faculties of New York University Rory Meyers College of Nursing (NYU) and Long Island University College of Pharmacy (LIU) partnered to develop a high-fidelity, Sim-IPE to integrate care of the older adult with multiple chronic cardiovascular conditions into both curricula. All IPE students had completed relevant coursework in health promotion, pharmacology and diagnosis and management of chronic conditions.

\section{Methods}

During two high-fidelity simulations over two consecutive years, advanced practice nursing students assumed the role of the primary care APRN and their student counterparts, the Doctor of Pharmacy students, practiced their role as pharmacists collaboratively in an outpatient clinic setting. This educational opportunity allowed students to work together to apply critical thinking skills to their assessments, develop differential diagnoses and generate clinical decisions in a safe learning environment. The simulation scenario included skilled debriefing sessions with feedback from instructors, student-colleagues, and the simulated patient (21).

\section{Sim-IPE design}

Faculty utilized the International Nursing Association for Clinical Simulation and Learning (INACSL) outcomes and objectives and design standards (Box 1) to develop the objectives $(B o x 2)$ and scenario, guided by the IPEC competencies $(3,22)$. The high-fidelity, Sim-IPE, multiple-comorbidities simulation, was developed as a 90 -minute simulation experience. Table 1 is a schematic of the incorporation of the IPEC Competencies into the scenario design.

Box 1 INACSL standards of best practice: simulation design

1. Perform a needs assessment to provide foundational evidence

2. Construct measureable objectives

3. Structure the format based on the purpose, theory, and appropriate simulation modality

4. Design the scenario or case to provide the context for the simulation experience

5. Use the appropriate type of fidelity to create the required perception of realism

6. Maintain a facilitative approach that is participant-centered and driven by the objectives

7. Begin the simulation with a prebriefing

8. Follow the simulation with a debriefing session

9. Include an evaluation of the participants, experience, facility, and facilitators

10. Provide preparation materials and resources to meet objectives

11. Pilot test the simulation prior to full implementation

INACSL, International Nursing Association for Clinical Simulation and Learning. 
Box 2 Multiple-comorbidities simulation learning objectives

At the conclusion of this simulation, the IPE student teams will collaborate to:

1. Demonstrate an organized focused health history

2. Demonstrate an accurate focused physical exam

3. Interpret labs/diagnostic tests accurately

4. Communicate their skills during history taking, the physical exam, and the explanation of treatment plan

5. Generate a differential diagnostic list of possible diagnoses

6. Communicate their findings concisely

7. Create a coordinated treatment plan for the diagnosis

8. Describe the roles and responsibilities of the members of an IP team and appreciate their unique contributions to teambased approaches to care

IPE, interprofessional education; IP, interprofessional.

\section{Mobile technology and clinical decision support (CDS) tools}

The introductory clinical, differential diagnosis course for primary care and family NP students at NYU, entitled Common Health Problems Across the Adult Lifespan, includes high-fidelity, standardized patient-centered simulation that utilizes mobile technology with access to CDS tools. CDS tools are designed to help process enormous amounts of digital data to suggest next steps for nursing interventions, alert nurses to available information they may not have noted, or catch potential problems, such as dangerous medication interactions (23). CDS is any tool that provides clinicians, patients, caregivers, or other members of the healthcare team with information that is filtered or targeted to a specific person or situation (23). NYU simulation faculty at the Clinical Simulation Learning Center (CSLC) integrate i-pad technology and smart phone decision support software $\left(\mathrm{UpToDate}^{\odot}\right.$, Lexicomp $\left.^{\odot}\right)$ to develop real-time decision making. LIU students used clinical resources available through LIU Library Learning Center including, but not limited to UpToDate ${ }^{\odot}$, Lexicomp ${ }^{\odot}$, etc.

\section{Multiple-comorbidities simulation}

NYU NP students in collaboration with LIU pharmacy students were introduced to a standardized patient with symptoms of uncontrolled type 2 diabetes mellitus, hypertension, and hyperlipidemia with untreated tobacco dependence and newly diagnosed left ventricular 


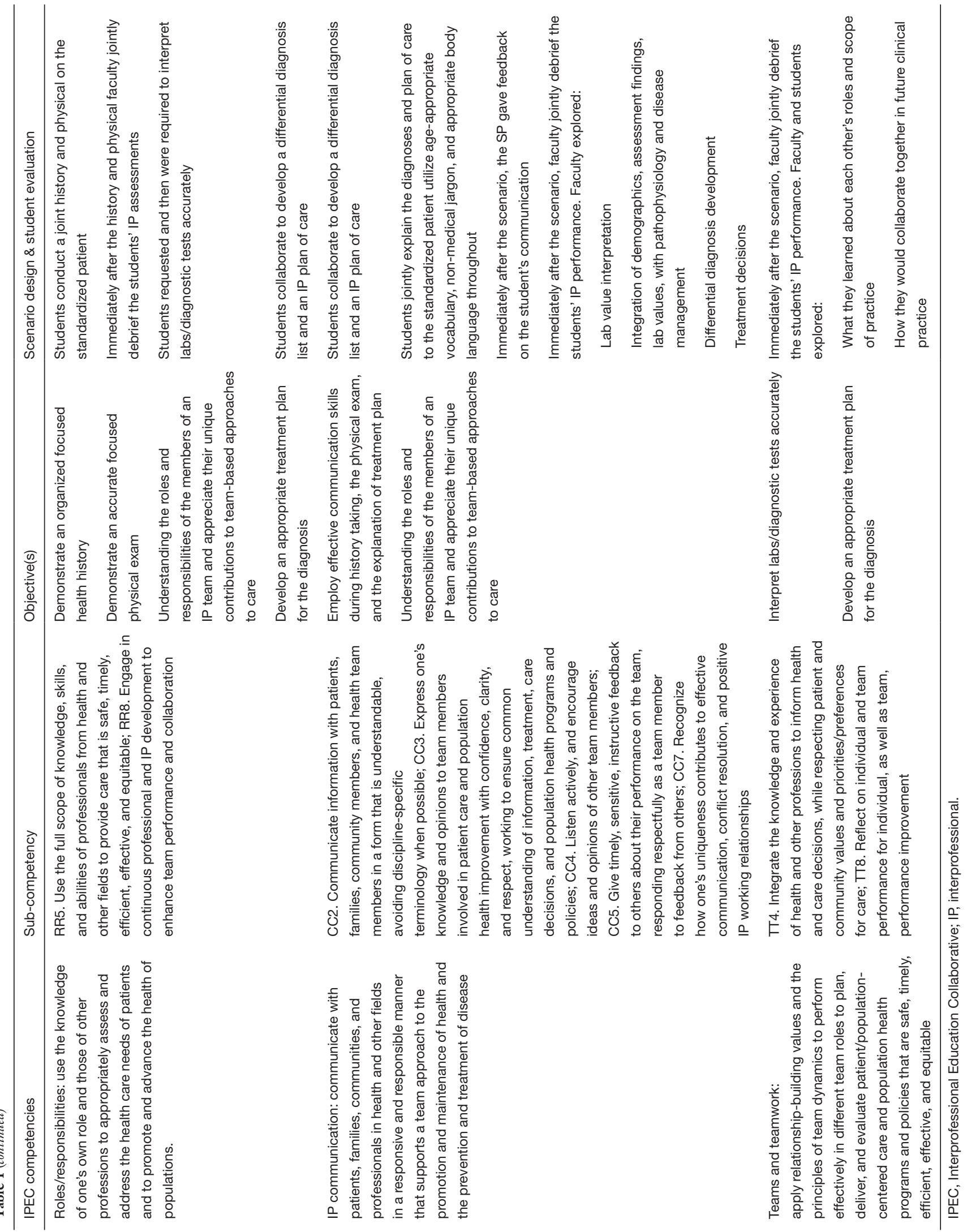


hypertrophy (LVH). During the IP experience, the clinical objectives required IP student teams to collaboratively take an organized and accurate patient health history, perform a physical examination, and generate a differential diagnosis list, which included a synthesis of patient demographics, physical assessment findings, lab values and diagnostic interpretations. Subsequently, IP teams of students listed their top diagnoses, and developed a comprehensive treatment plan in which they discussed lifestyle modifications, prescribed medications, reviewed the mechanisms of action and side effects of the prescribed drugs, and together, with the patient and family, developed a comprehensive, patient and family-centered comprehensive care plan.

The steps of the simulation protocol included:

(I) The NP and pharmacy students conduct a patient health history, perform a physical examination, and collect pertinent medication information relevant to the chief complaint (20 minutes).

(II) Faculty debrief the IP student teams' assessment and students request labs and diagnostic information based on their exam findings (10 minutes). Students must provide rationale for each test ordered, with coaching from faculty if needed.

(III) The IP student team assembles in a different room where, collectively, they analyze labs and imaging, then synthesize their conclusions together with the history and physical findings. Utilizing whichever guidelines and resources they choose, they collaboratively develop a differential diagnosis list and devise a comprehensive treatment plan (30 minutes).

(IV) The IP student teams return to the exam room and present their diagnosis, proposed treatment plan, and educate the standardized patient on his/her medications. Table 1 is a schematic of the integration of IPEC core competencies into the multiple-comorbidities simulation. After that, students debrief the entire simulation experience and reflect on their own IP experiences with the faculty members.

(V) Following completion of the IPE-simulation experience, IP faculty debriefed the team on the simulation experience using the Promoting Excellence and Reflective Learning in Simulation (PEARLS) framework (24). PEARLS' framework includes several sequential steps to guide debriefing including setting the scene for the debriefing, the initial reactions, the discussion phase, the analysis phase of decisions that were made, the applicability to future practice and the summary of keytakeaways (24).

(VI) After the debriefing, IPE participants reflected on their own IP experiences with the faculty members. This is consistent with a utilization-focused evaluation in which participants evaluated the usefulness of the simulation experience in terms of the relevance to their future practice.

\section{Interprofessional Collaborative Competency Attainment Survey (ICCAS)}

The ICCAS asks students to assess their perceptions of IP competency attainment before and after an IP educational experience and measures six overarching IP domains including communication, collaboration, roles and responsibilities, collaborative patient/family approach, conflict resolution and team functioning (25). Student perceptions of IP competency attainment are measured on an even point Likert scale ( $1=$ strongly disagree to $6=$ strongly agree) with a seventh "not applicable" option. The ICCAS psychometrics are reliable (pre-program assessment: Cronbach's alpha for Factor 1 is 0.961 and Factor 2 is 0.941; post-program Cronbach's alpha is 0.981) and predict meaningful outcomes regarding attitudes toward IP competency attainment (25).

The ICCAS responses were voluntary, administered via an anonymous data collection form that was developed on Qualtrics ${ }^{\odot}$. The pre- and post-surveys were accessed via a link sent to students' iPhones 24-hour prior to, and immediately after the simulation scenario was completed.

\section{Results}

Of the 115 pharmacy and nursing students who participated in the IPE event, 96 students completed the pre- and postsurveys for a response rate of $83 \%$. The pre-and postsurvey data was then combined and aggregated. Means and standard deviation was calculated for each item. Each preand post-survey questions was then analyzed using paired $t$-tests with $\mathrm{P}$ value significance set at $>0.05$. STATA V12 was used for analysis. Expedited Institutional Review Board approval was obtained at each university.

\section{Overall student satisfaction}

Ninety-six pharmacy (55.6\%) and NP (44.4\%) students 
Table 2 Student satisfaction with the 2018 and 2019 chronic comorbidities IP simulation events

\begin{tabular}{|c|c|c|}
\hline IPE event (1 excellent, 5 poor) & Mean & SD \\
\hline Overall, how would you rate this IPE event? & 1.38 & 0.54 \\
\hline How useful was this IPE event in appreciating the roles of other healthcare providers? & 1.43 & 0.49 \\
\hline In your judgement how well organized was the event? & 1.34 & 0.36 \\
\hline How engaging were the faculty members with the students at this IPE event? & 1.23 & 0.20 \\
\hline
\end{tabular}

IP, interprofessional; IPE, interprofessional education.

completed the pre- and post- surveys and participated in the two simulation experiences over two consecutive spring semesters in 2018 and 2019. This was the first IPE experience for $27.4 \%$ of students while $72.6 \%$ of students reported being involved in a prior IP learning activity. The overall satisfaction rating of the experience was measured on a 5 -point Likert scale $(1=$ excellent to $5=$ poor $)$, and results revealed students were very satisfied with the experience $(M=1.378, S D=0.54)$. The students found the simulation useful in appreciating each other's roles $(M=1.43$, $\mathrm{SD}=0.49)$, well-organized $(M=1.34, \mathrm{SD}=0.36)$, and the faculty highly engaged $(M=1.23, \mathrm{SD}=0.20)$ (Table 2$)$.

\section{Pre- and post-simulation ICCAS}

Pre- and post-survey result statistics were calculated using paired $t$-tests of aggregated data from both semesters with significance level of testing $<0.05$. Significant differences between pre- and post-means for each question are starred in Table 3. Significant improvement in all of the IP collaborative scores were seen ubiquitously across all six domains of IPE competence, including communication, roles and responsibilities, collaborative patient/familycentered approach, conflict management, and team functioning.

\section{Discussion}

IPE in healthcare education is one of the main pedagogical strategies used in providing safe, efficient and effective patient-centered care in healthcare settings $(26,27)$. While there is some evidence documenting the effectiveness of high-fidelity simulation in undergraduate nursing programs, there is limited evidence illustrating the benefits that IPE provides for graduate healthcare profession students (27). A systematic review including 10 studies examining the effectiveness of simulation-based education programs in NP programs revealed that students preferred learning and evaluation through patient simulation over traditional paper and pencil exams (27). Similar to our evaluation study, NP students enjoyed the overall simulation experience and were overwhelmingly satisfied. However, this systematic review did not include IP students.

There are few studies that have evaluated IP simulations with graduate students. An exploratory, quantitative and qualitative pilot study was conducted with ten family $\mathrm{NP}$ and ten medical students who participated in one standardized IPE-simulation involving a patient who presented to the ER with a fracture. Both groups of students reported increased confidence in working as part of a team after the simulation, but acknowledged the challenges that teamwork can precipitate in the real world, including the power dynamics, time constraints and complex communication issues (28). One student reported simulation as "idealistic" and not reflecting the pressures of the real world.

Haber et al. [2017] reported on a pre-test, posttest evaluation of an IP experience conducted over two consecutive years involving standardized patients with type II diabetes mellitus, periodontitis and multiple psychosocial barriers to primary care. Three hundred and eighteen of $326(98 \%)$ NP, midwifery (MW), dental and medical students completed the ICCAS scale with a statistically significant improvement in mean scores after completion of the simulation (29). In one of the years, medical students pre-test scores were significantly lower in collaboration, roles and responsibilities and dental students pre-test mean score were lower in collaboration. The authors speculated that the discrepancy may be attributed to the increased exposure to IPE that NP/MW students receive in their curricula (29). Additionally, many NPs/MWs have worked as nurses prior to graduate school and may have more experience collaborating with other professionals.

Many barriers exist in developing and implementing IPE activities. Some of the barriers include different level of students' learning needs and knowledge and understanding 
Table 3 IP collaborative competency attainment survey results

\begin{tabular}{|c|c|c|c|c|c|}
\hline \multirow[t]{2}{*}{ ICCAS survey items } & \multicolumn{2}{|c|}{ Pre-survey $(\mathrm{n}=96)$} & \multicolumn{2}{|c|}{ Post-survey $(n=96)$} & \multirow{2}{*}{$\begin{array}{l}\text { Significant } \\
\text { differences }\end{array}$} \\
\hline & Mean & SD & Mean & SD & \\
\hline \multicolumn{6}{|l|}{ Communication } \\
\hline 1. Promote effective communication among members of an IP team & 4.84 & 1.04 & 5.50 & 0.90 & 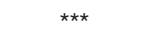 \\
\hline 2. Actively listen to IP team members' ideas and concerns & 4.96 & 1.07 & 5.57 & 0.89 & *** \\
\hline 3. Express my ideas and concerns without being judgmental & 4.86 & 1.06 & 5.54 & 0.96 & *** \\
\hline 4. Provide constructive feedback to IP team members & 4.78 & 1.03 & 5.52 & 0.91 & 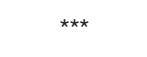 \\
\hline 5. Express my ideas and concerns in a clear, concise manner & 4.79 & 1.06 & 5.53 & 0.89 & $\star * *$ \\
\hline \multicolumn{6}{|l|}{ Collaboration } \\
\hline 6. Seek out IP team members to address issues & 4.79 & 1.08 & 5.56 & 0.80 & $\star \star \star *$ \\
\hline 7. Work effectively with IP team members to enhance care & 4.79 & 1.08 & 5.57 & 0.89 & *** \\
\hline 8. Learn with, from and about IP team members to enhance care & 4.83 & 1.08 & 5.57 & 0.89 & *** \\
\hline \multicolumn{6}{|l|}{ Roles and responsibilities } \\
\hline 9. Identify and describe my abilities and contributions to the IP team & 4.71 & 1.03 & 5.75 & 0.93 & $\star \star \star ~$ \\
\hline 10. Be accountable for my contributions to the IP team & 4.86 & 1.04 & 5.58 & 0.88 & *** \\
\hline 11. Understand the abilities and contributions of IP team members & 4.80 & 1.03 & 5.75 & 0.93 & 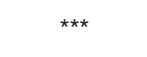 \\
\hline $\begin{array}{l}\text { 12. Recognize how others' skills and knowledge complement and } \\
\text { overlap with my own }\end{array}$ & 4.78 & 1.05 & 5.75 & 0.93 & $\star \star \star *$ \\
\hline \multicolumn{6}{|l|}{ Collaborative patient/family-centered approach } \\
\hline $\begin{array}{l}\text { 13. Use an IP team approach with the patient to assess the health } \\
\text { situation }\end{array}$ & 4.84 & 1.05 & 5.58 & 0.89 & *** \\
\hline $\begin{array}{l}\text { 14. Use an IP team approach with the patient to provide whole person } \\
\text { care }\end{array}$ & 4.81 & 1.02 & 5.53 & 0.89 & 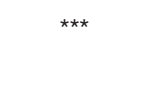 \\
\hline 15. Include the patient/family in decision-making & 4.82 & 1.06 & 5.53 & 0.92 & *** \\
\hline \multicolumn{6}{|l|}{ Conflict management/resolution } \\
\hline 16. Actively listen to the perspectives of IP team members & 4.97 & 1.07 & 5.59 & 0.46 & *** \\
\hline 17. Take into account the ideas of IP team members & 4.93 & 1.02 & 5.57 & 0.89 & *** \\
\hline 18. Address team conflict in a respectful manner & 4.91 & 1.09 & 5.59 & 0.90 & *** \\
\hline \multicolumn{6}{|l|}{ Team functioning } \\
\hline 19. Develop an effective care plan with IP team members & 4.81 & 1.08 & 5.59 & 0.87 & 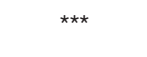 \\
\hline 20. Negotiate responsibilities within overlapping scopes of practice & 4.81 & 1.05 & 5.56 & 0.91 & 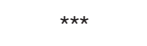 \\
\hline
\end{tabular}

***, $\mathrm{P}<0.001 .1$ = strongly disagree; $2=$ moderately disagree; $3=$ slightly disagree; $4=$ slightly agree; $5=$ moderately agree; $6=$ strongly agree. IP, interprofessional; ICCAS, Interprofessional Collaborative Competency Attainment Survey.

of other health profession's roles and responsibilities (30-32). To overcome those barriers students in their last professional year programs participated in this activity and their level of knowledge of other health profession's roles and responsibilities were assessed using ICCAS survey. Similar to the aforementioned evaluation studies, the results of the pre- and post-ICCAS surveys at NYU overwhelmingly demonstrated student perceptions of IP competency attainment significantly improved after this high-fidelity, Sim-IPE experience in all six domains (significant differences $\mathrm{P}<0.001$ ). Even though three quarters of the students indicated that they had some prior IPE 
participation experience, there was statistically significant difference in student perceptions of IPE competency attainment $(\mathrm{P}<0.001$ in all six domains). This particular event showcased our students' ability to collaborate in the care of older adults with multiple chronic cardiovascular conditions $(\mathrm{P}<0.001$ in Collaboration and Collaborative Patient/Family-Centered Approach domains). It also demonstrated the students' use of the CDS technology $\left(\mathrm{UpToDate}^{\odot}{ }\right.$ Lippincott's Nursing Advisor $^{\odot}$ ) in real time, to review guidelines, and make evidence-based recommendations in development of the IP management plans. This high-fidelity, Sim-IPE enhanced awareness of their respective roles and responsibilities as members of health care team while providing meaningful and relevant inter-professional experiences. Faculty emphasized strong communication and collaboration skills in the design of the simulation experience as these skills are essential for students transitioning into an advanced practice nursing or pharmacist role.

\section{Limitations}

This utilization-focused evaluation has several limitations. First, we included only one cardiovascular chronic disease IPE-Sim which was conducted each year over the course of 2 years. Second, aggregate means were used to reflect changes in students' self-assessments of their IPE competency and satisfaction. Third, while students perceived improvements in IPE competency, it is not known whether those improvements occurred. Finally, faculty evaluations were not reported.

\section{Conclusions}

Effective collaborative practice in healthcare improves patient outcomes by decreasing clinical error rates, length of hospital stays, and mortality rates, while improving patient care and safety, access to and coordination of healthservices, and health outcomes for people with chronic diseases (26). High fidelity, Sim-IPE is an effective pedagogy to teach future APRNs and pharmacists to collaborate; improving communication, reducing potential medical errors, and improving the patient experience and quality of life. IPE programs should be expanded and integrated into all graduate curricula to prepare students to deliver high quality patient-centered care, work effectively in an IP team, communicate productively, and understand each other's roles. Future research studies need to be conducted to examine the effect of IPE-simulations threaded through graduate curricula on the post-graduates' performance of IPEC competencies in actual clinical settings.

\section{Acknowledgments}

Funding: This work was supported by the Hugoton Foundation, to integrate palliative care of the seriously ill into nursing simulation curriculum.

\section{Footnote}

Provenance and Peer Review: This article was commissioned by the Guest Editor (Mei R. Fu) for the series "Real-Time Detection and Management of Chronic Illnesses" published in mHealth. The article was sent for external peer review organized by the Guest Editor and the editorial office.

Conflicts of Interest: All authors have completed the ICMJE uniform disclosure form (available at http://dx.doi. org/10.21037/mhealth-19-216). The series "Real-Time Detection and Management of Chronic Illnesses"was commissioned by the editorial office without any funding or sponsorship. MB discloses that she is a member of an advisory board for Express Scripts, determining whether specialized medications for rare diseases, belong in the specialized pharmacy. The work on the Advisory Board has no relationship to this work. The authors have no other conflicts of interest to declare.

Ethical Statement: The authors are accountable for all aspects of the work in ensuring that questions related to the accuracy or integrity of any part of the work are appropriately investigated and resolved.

Open Access Statement: This is an Open Access article distributed in accordance with the Creative Commons Attribution-NonCommercial-NoDerivs 4.0 International License (CC BY-NC-ND 4.0), which permits the noncommercial replication and distribution of the article with the strict proviso that no changes or edits are made and the original work is properly cited (including links to both the formal publication through the relevant DOI and the license). See: https://creativecommons.org/licenses/by-nc-nd/4.0/.

\section{References}

1. World Health Organization. Framework for action on 
interprofessional education and collaborative practice. Geneva: World Health Organization, 2010.

2. Buring SM, Bhushan A, Broeseker A, et al. Interprofessional education: definitions, student competencies, and guidelines for implementation. Am J Pharm Educ 2009;73:59.

3. Interprofessional Education Collaborative. Core Competencies for Interprofessional Collaborative Practice. Washington DC: Interprofessional Education Collaborative, 2011.

4. Remington TL, Foulk MA, Williams BC. Evaluation of evidence for interprofessional education. Am J Pharm Educ 2006;70:66.

5. Accreditation Council for Pharmacy Education (ACPE). Accreditation Standards and Key Elements for the Professional Program in Pharmacy Leading to the Doctor of Pharmacy Degree, "Standards 2016". Chicago: Accreditation Council for Pharmacy Education, 2016.

6. Commission on Collegiate Nursing Education (CCNE). Standard for Accreditation of Baccalaureate and Graduate Nursing Programs. Washington DC: CCNE, 2018.

7. Seybert AL. Patient simulation in pharmacy education. Am J Pharm Educ 2011;75:187.

8. Branch C. Pharmacy students' learning and satisfaction with high-fidelity simulation to teach drug-induced dyspepsia. Am J Pharm Educ 2013;77:30.

9. Vyas D, Bray BS, Wilson MN. Use of simulation-based teaching methodologies in US colleges and schools of pharmacy. Am J Pharm Educ 2013;77:53.

10. American Association of the College of Nursing \& National Organization for Nurse Practitioner Faculty. Criteria for the Evaluation of Nurse Practitioner Programs. 5th ed. 2016. Available online: https://cdn. ymaws.com/www.nonpf.org/resource/resmgr/Docs/ EvalCriteria2016Final.pdf

11. Wu XF, Chang Y, Yin H. Environmental research on the element of constructing practical teaching system for nursing high-fidelity simulation. Ekoloji 2019;28:4611-4.

12. INACSL Standards Committee. INACSL standards of best practice simulation: simulation-enhanced interprofessional education (Sim-IPE). Clin Simul Nurs 2016;12:S34-8.

13. Victor J, Ruppert W, Ballasy S. Examining the relationships between clinical judgment, simulation performance, and clinical performance. Nurse Educ 2017;42:236-9.

14. Paige JT, Kozmenko V, Yang T, et al. Attitudinal changes resulting from repetitive training of operating room personnel using of high-fidelity simulation at the point of care. Am Surg 2009;75:584-90; discussion 590-1.

15. Lopreiato JO, Downing D, Gammon W, et al. Healthcare simulation dictionary. 1st ed. 2016. Available online: https://www.ssih.org/dictionary

16. National Council on Aging. The United States of Aging Survey National Findings. 2012. Available online: https:// www.ncoa.org/wp-content/uploads/8-3-12-US-of-AgingSurvey-Fact-Sheet-National-FINAL.pdf

17. Devitt M. CDC data show U.S. life expectancy continues to decline. Am Fam Physician 2018. Available online: https://www.aafp.org/news/health-of-the public/20181210 lifeexpectdrop.html

18. Centers for Disease Control and Prevention. Data and statistics. 2019. Available online: https://www.cdc.gov/ chronicdisease/index.htm

19. Bodenheimer T, Wagner EH, Grumbach K. Improving primary care for patients with chronic illness. JAMA 2002;288:1775-9.

20. Bodenheimer T, Wagner EH, Grumbach K. Improving primary care for patients with chronic illness: the chronic care model, Part 2. JAMA 2002;288:1909-14.

21. Kim J, Park JH, Shin S. Effectiveness of simulation-based nursing education depending on fidelity: a meta-analysis. BMC Med Educ 2016;16:152.

22. INACSL Standards Committee. INACSL standards of best practice: simulationSM, simulation design. Clin Simul Nurs 2016;12:S5-12.

23. Bresnick J. Understanding the basics of clinical decision support systems. 2017. Available online: https:// healthitanalytics.com/features/understanding-the-basicsof-clinical-decision-support-systems

24. Eppich W, Cheng A. Promoting Excellence and Reflective Learning in Simulation (PEARLS): development and rationale for a blended approach to health care simulation debriefing. Simul Healthc 2015;10:106-15.

25. Archibald D, Trumpower D, MacDonald CJ. Validation of the interprofessional collaborative competency attainment survey (ICCAS). J Interprof Care 2014;28:553-8.

26. Hopkins D. Framework for Action on Interprofessional Education \& Collaborative Practice. Geneva: World Health Organization, 2010.

27. Warren JN, Luctkar-Flude M, Godfrey C, et al. A systematic review of the effectiveness of simulation-based education on satisfaction and learning outcomes in nurse practitioner programs. Nurse Educ Today 2016;46:99-108.

28. Tankimovich M, Swails J, Hamburger M. Nurse practitioner and medical students' perceptions of teamwork before and after a standardized patient pilot simulation. 
Nurs Educ Perspect 2020;41:171-3.

29. Haber J, Hartnett E, Allen K, et al. The impact of oralsystemic health on advancing interprofessional education outcomes. J Dent Educ 2017;81:140-8.

30. Ateah CA, Snow W, Wener P, et al. Stereotyping as a barrier to collaboration: does interprofessional education make a difference? Nurse Educ Today 2011;31:208-13.

31. Sunguya BF, Hinthong $W$, Jimba $M$, et al. Interprofessional education for whom? --challenges and lessons learned

doi: $10.21037 /$ mhealth-19-216

Cite this article as: Tilley CP, Roitman J, Zafra KP, Brennan M. Real-time, simulation-enhanced interprofessional education in the care of older adults with multiple chronic comorbidities: a utilization-focused evaluation. mHealth 2021;7:3. from its implementation in developed countries and their application to developing countries: a systematic review. PLoS One 2014;9:e96724.

32. Homeyer S, Hoffmann W, Hingst $P$, et al. Effects of interprofessional education for medical and nursing students: enablers, barriers and expectations for optimizing future interprofessional collaboration - a qualitative study. BMC Nurs 2018;17:13. 